OPEN ACCESS

Edited by:

Seth Davin Norrholm,

Emory University School of Medicine. United States

Reviewed by:

Jeffrey B. Rosen,

University of Delaware, United States

Travis D. Goode,

Harvard University, United States

${ }^{*}$ Correspondence:

Paul Pauli

pauli@psychologie.uni-wuerzburg.de

Received: 01 February 2019 Accepted: 21 June 2019

Published: 17 July 2019

Citation: Neueder D, Andreatta M and Pauli P (2019) Contextual Fear Conditioning and Fear Generalization in Individuals With Panic Attacks.

Front. Behav. Neurosci. 13:152. doi: 10.3389/fnbeh.2019.00152

\section{Contextual Fear Conditioning and Fear Generalization in Individuals With Panic Attacks}

\author{
Dorothea Neueder ${ }^{1}$, Marta Andreatta ${ }^{1}$ and Paul Pauli ${ }^{1,2 *}$ \\ ${ }^{1}$ Department of Psychology (Biological Psychology, Clinical Psychology, and Psychotherapy), University of Würzburg, \\ Würzburg, Germany, ${ }^{2}$ Center for Mental Health, Medical Faculty, University of Würzburg, Würzburg, Germany
}

Context conditioning is characterized by unpredictable threat and its generalization may constitute risk factors for panic disorder (PD). Therefore, we examined differences between individuals with panic attacks (PA; $N=21)$ and healthy controls $(H C, N=22)$ in contextual learning and context generalization using a virtual reality (VR) paradigm. Successful context conditioning was indicated in both groups by higher arousal, anxiety and contingency ratings, and increased startle responses and skin conductance levels (SCLS) in an anxiety context (CTX+) where an aversive unconditioned stimulus (US) occurred unpredictably vs. a safety context (CTX-). PA compared to HC exhibited increased differential responding to CTX+ vs. CTX- and overgeneralization of contextual anxiety on an evaluative verbal level, but not on a physiological level. We conclude that increased contextual conditioning and contextual generalization may constitute risk factors for PD or agoraphobia contributing to the characteristic avoidance of anxiety contexts and withdrawal to safety contexts and that evaluative cognitive process may play a major role.

Keywords: contextual fear conditioning, anxiety generalization, startle response, panic disorder, virtual reality

\section{INTRODUCTION}

Panic disorder (PD) is one of the most disabling of anxiety disorders affecting about 7.8 million individuals in Europe (Wittchen et al., 2011). Acute panic attacks (PA) of intense fear and anticipatory anxiety towards forthcoming attacks are constitutive symptoms of PD (DSM-5, American Psychiatric Association, 2013). Oversensitivity to unpredictable aversive events, but not towards predictable threat, is assumed to be a risk factor for PD (Grillon et al., 1994, 2009; Grillon, 2008; Nelson et al., 2013; Gorka et al., 2017). Consequently, PD patients are assumed to respond with sustained fear in the context in which unpredictable threat was experienced and therefore is expected again, and the concomitant hypervigilance towards potential threat is presumed to facilitate the reoccurrence of additional PA (Bașoğlu et al., 1994).

Overgeneralization of conditioned fear responses to stimuli that resemble the original threateliciting stimulus (generalization stimuli, GSs) but have never been paired with aversive events is discussed as another risk factor for PD (Lissek, 2012; Dymond et al., 2015). Such overgeneralization of fear in PD was found for discrete stimuli predicting threat but was not examined for contexts associated with unpredictable threat so far, although the latter seems highly relevant for PD. 
Following the seminal studies of Baas et al. (2004, 2008), we developed a differential context conditioning paradigm realized with virtual reality (VR), which allows participants to immerse in various ecologically valid computer-based virtual environments (Tröger et al., 2012; Glotzbach-Schoon et al., 2013a). Here, a specific context (anxiety context, CTX+) becomes associated with unpredictable threat and later induces sustained anxious apprehension, while another context (safety context, CTX-) never becomes associated with threat and therefore implies safety. Using this VR paradigm, we successfully demonstrated context conditioning in healthy individuals, thus they rated CTX+ vs. CTX - more anxiogenic, arousing, negatively valenced, and more strongly associated with the unconditioned stimuli (US), and they avoided entering CTX+ (Glotzbach et al., 2012; Glotzbach-Schoon et al., 2013b,c). In addition, we observed startle potentiation and higher skin conductance level (SCL) in CTX+ vs. CTX- (Glotzbach-Schoon et al., 2013b,c; Andreatta et al., 2015a, 2017; Genheimer et al., 2017) as well as stronger amygdala activation (Andreatta et al., 2015b). Importantly, we also found that trait anxiety, an assumed risk factor for anxiety disorders, modulates context conditioning (Glotzbach-Schoon et al., 2013c).

Recently, we advanced our VR paradigm to study the generalization of contextual anxiety. By implementing a generalization context (G-CTX) that shares physical properties of $\mathrm{CTX}+$ and CTX - equally, we were able to reveal generalization of verbal anxiety responses to G-CTX in healthy individuals and we found first indications that trait anxiety modulates generalization as well (Andreatta et al., 2015a).

The current study is that first examining individuals characterized by PA in comparison to healthy controls (HC) regarding context conditioning and generalization of conditioned anxiety. First, we hypothesized that individuals with PA show heightened context conditioning as assessed by verbal and physiological responses during the acquisition phase. Second, we expected that these individuals during the generalization test show persevering anxiety, i.e., greater CTX+ vs. CTX - differences, and overgeneralization of anxiety responses, i.e., greater G-CTX vs. CTX- differences.

\section{MATERIALS AND METHODS}

\section{Participants}

The final sample consisted of 21 individuals with current PA and 22 HC. Participants were recruited via advertisement on public websites and newspapers and were first screened by phone regarding experienced PA. Participants with PA had to report at least one PA during the last 2 weeks and $\mathrm{HC}$ had to be free of PA. Additional exclusion criteria were Beck Depression Inventory (BDI, Hautzinger et al., 2006) scores above 16 or above 9 for PA and HC, respectively. Because of the high comorbidity between $\mathrm{PD}$ and major depression (Roy-Byrne et al., 2000) it is virtually impossible to recruit individuals with PA without any symptoms of depression. However, as we did not want to examine participants with dominant depressive symptoms, we excluded PA participants who fulfilled clinically relevant criteria of depression as indicated by a BDI above 16. For $\mathrm{HC}$, we considered a BDI score of above 9 as indicating sub-clinical symptoms of depression.

Exclusion criteria for all participants were current use of psychoactive drugs or psychotherapy, severe neurological diseases or pregnancy. Ten participants had to be excluded due to high BDI scores $(n=3)$, motion sickness $(n=2)$, or negligible startle responses $(n=5$; mean startle amplitude $\leq 5 \mathrm{mV})$. All participants gave informed consent approved by the Ethics Committee of the Medical Faculty of the University of Würzburg and were compensated for their participation with $30 €$.

\section{Material and Apparatus}

Unconditioned stimuli (US) were mildly painful electric stimuli delivered with a frequency of $50 \mathrm{~Hz}$ and $200 \mathrm{~ms}$ duration by a constant current stimulator (Digitimer DS7A, Digitimer Limited; $400 \mathrm{~V}, \max 9.99 \mathrm{~mA}$ ) to the dominant forearm via two gold-plated stainless-steel surface electrodes of $9 \mathrm{~mm}$ diameter and $30 \mathrm{~mm}$ spacing. Intensity was individually adjusted in two ascending and descending series (Andreatta et al., 2010) and then increased by $30 \%$ to avoid habituation.

Contextual stimuli (CTX) were virtual rooms designed with the Source Engine (Valve Corporation) with identical spatial surface but different layout (for details see Andreatta et al., 2015a) and presented via a Z800 3D Visor head-mounted display (HMD, eMagin) controlled by the software CyberSession (VT+ $\mathrm{GmbH}$, Germany).

Acoustic startle probes were $103 \mathrm{~dB}$ bursts of white noise presented for $50 \mathrm{~ms}$ binaurally via headphones.

\section{Ratings}

Participants rated the valence, arousal, anxiety and contingency they had experienced in the virtual rooms on a visual analog scale (VAS) ranging from 0 to 100 at predefined time points during the experiment (see "Procedure" section). More detailed, according for valence 0 depicted negative valuation, 100 positive valuation of the respective room. In arousal 0 stood for no arousal up 100 for very high arousal during the visit of the room. In anxiety 0 mean no anxiety at all, 100 very high anxiety. For contingency, VAS ranged from 0 (no US expectation) to 100 (US surely expected).

Participants were labeled "contingency aware" if the CTX+ minus CTX - difference in contingency ratings was $\geq 70$.

\section{Questionnaires}

All participants completed the four sub-questionnaires of the Comprehensive Panic Profile (CPP, Clum et al., 1995), a composite measure that reliably evaluates panic symptoms and outcomes (Clum et al., 1990). The Panic Frequency Scale (PFS), Panic Attack Symptoms Questionnaire (PASQ), Panic Attack Cognitions Questionnaire (PACQ), and Avoidance Questionnaire (AQ) were used to quantify the number of PA, the severity of symptoms and the degree of preoccupation with typical cognitions during a PA and the level of avoidance of panic-related places and situations, respectively (Clum et al., 1990, 1995). Furthermore, participants completed the AnxietySensitivity Index (ASI, Peterson and Reiss, 1992; German Version: Alpers and Pauli, 2001), the State-Trait Anxiety 
Inventory (STAI, Laux et al., 1981), the Positive and Negative Affect Schedule (PANAS, Krohne et al., 1996), and the BDI (Hautzinger et al., 2006).

\section{Procedure}

After completion of questionnaires and electrode attachment, pain thresholds were assessed. Then, seven startle probes were presented every $7-14 \mathrm{~s}$ to habituate initial startle reactivity (Blumenthal et al., 2005). The experiment consisted of four experimental phases interspersed by online ratings.

During the exploration phase, participants actively explored CTX+ and CTX - for 2 min each using a joystick.

During two identical acquisition phases (ACQ 1 and 2), participants were passively guided through the virtual offices on two pre-recorded paths. Paths started from the corridor (inter-trial interval, ITI; lasting about $20 \mathrm{~s}$, entered one virtual room, in which participants remained for $60 \mathrm{~s}$ and ended with the exit from the office. Participants entered each room three times in a pseudo-randomized order so that the same room was never entered in more than two consecutive trials. Only CTX+ was paired with one to three US during each trial, resulting in six US per acquisition phase. Altogether, 32 startle probes were delivered (six startle probes per context and four during the ITI per acquisition phase). The shortest time interval between two startle probes, between probe and US or between two US was 10 s (see Grillon et al., 2006), and these stimuli were never delivered during the first and the last $7 \mathrm{~s}$ of each room visit to prevent possible associations with the doors.

During the generalization phase (GEN), participants were guided through CTX+, CTX- and G-CTX, three times each. The sequence of context presentation was pseudo-randomized. No US were delivered. Six startle probes were presented per room and five during the ITI.

After each phase (Exploration, ACQ1, ACQ2, GEN), ratings of valence, arousal, anxiety, and contingency were assessed (the latter not after Exploration).

\section{Data Reduction and Statistical Analysis}

Physiological responses were recorded continuously with a V-Amp 16 (Version 1.03.0004, BrainProducts Inc., 1,000 Hz sampling rate, $50 \mathrm{~Hz}$ notch-filter). Startle responses were registered as electromyographic activity of the left orbicularis oculi muscle with $5 \mathrm{~mm} \mathrm{Ag/Ag-Cl} \mathrm{electrodes} \mathrm{(see} \mathrm{Blumenthal}$ et al., 2005). Ground and reference electrodes were adhered over the right and the left mastoids, respectively. Impedance of the electrodes was kept below $10 \mathrm{k} \Omega$. Startle data was offline filtered using $28 \mathrm{~Hz}$ low cut-off and $400 \mathrm{~Hz}$ high cut-off filters, then rectified and smoothed $(50 \mathrm{~ms}$ moving average) and segmented from $50 \mathrm{~ms}$ before and 1,000 ms after startle probe onset and finally baseline corrected. Startle amplitude was defined as the maximum of the integrated response curve relative to baseline within $20 \mathrm{~ms}$ to $120 \mathrm{~ms}$ after probe onset. We scored responses manually and excluded trials with excessive baseline shifts or movement artifacts (signal $\geq 5 \mu \mathrm{V}$ ). Startle magnitude was averaged for each condition (CTX+, CTX-, G-CTX, and ITI), separately for acquisition and generalization, but at least two valid responses per condition were required for inclusion in further analysis. Participants with a mean startle magnitude $<5 \mu \mathrm{V}$ were excluded as non-responders $(n=3)$. Raw data were withinsubjects transformed in $\mathrm{z}$-scores and then in T-scores. Responses to the contexts were calculated as differences in startle magnitude during the visit of the respective context minus preceding ITI responses to control individual baseline differences (Blumenthal et al., 2005).

SCL was recorded with two $8 \mathrm{~mm} \mathrm{Ag} / \mathrm{AgCl}$ electrodes, fixed on the palm of the non-dominant hand. We applied a $1 \mathrm{~Hz}$ high cut-off filter offline and then averaged SCL separately for each condition across stay in a virtual context (i.e., $60 \mathrm{~s}$ excluding 10 safter US presentations. Finally, SCL data were square root transformed (Boucsein et al., 2012). No participant had to be excluded as non-responders (mean SCL $<0.02 \mu \mathrm{S}$ ).

\section{Data Analysis}

Statistics were performed with SPSS (Version 23.0, SPSS Inc., Chicago, IL, United States). Rating and physiological data were analyzed separately for exploration, ACQ and GEN with repeated-measures analysis of variances (ANOVAs) with between-subjects factor group (PA and $\mathrm{HC}$ ) and withinsubject factor context (exploration and acquisition phase: CTX+, CTX-; GEN: CTX+, CTX+, G-CTX); ANOVAs of acquisition additionally considered the within-subject factor phase (ACQ1, ACQ2). To follow up significant Group $\times$ Context interactions, we tested group differences on the basis of a priori defined discrimination indices as differences to CTX-; for ACQ, an increased discrimination index of CTX + minus CTXindicates better context discrimination and stronger acquisition of conditioned anxiety; for GEN, an increased discrimination index of $\mathrm{CTX}+$ minus $\mathrm{CTX}-$ (testCON) indicates more persisting anxiety responses, and an increased discrimination index of G-CTX minus CTX- (testGEN) indicates increased generalization of anxiety.

Significance level was $p<0.05$, and the Greenhouse-Geisser correction $(\mathrm{GG}-\varepsilon)$ was applied if necessary. Effect sizes were indicated by partial $\eta^{2}$.

\section{RESULTS}

\section{Demographics and Clinical Characteristics}

As summarized in Table 1, groups are comparable in gender ratio, age, objective and subjective US intensity, and contingency awareness (all ps $>0.191$ ). As expected, PA suffered from more PA $\left(F_{(1,42)}=57.18, p<0.001\right)$, more severely panic symptomatology $\left(F_{(1,42)}=66.69, p<0.001\right)$ and panic cognitions $\left(F_{(1,42)}=69.95, p<0.001\right)$, and avoided significantly more panic-associated situations $\left(F_{(1,42)}=38.23, p<0.001\right)$ than HC. Furthermore, PA scored higher in trait anxiety $\left(F_{(1,42)}=10.85\right.$, $p=0.002)$, anxiety sensitivity $\left(F_{(1,42)}=17.80, p<0.001\right)$, and $\operatorname{BDI}\left(F_{(1,42)}=23.80, p<0.001\right)$.

\section{Exploration Phase}

Analyses revealed no significant effects involving the factor context, that is contexts were rated as equivalent 
TABLE 1 | Demographic and psychometric data of participants with panic attacks (PA) and healthy controls (HC).

\begin{tabular}{|c|c|c|c|c|c|c|}
\hline & \multicolumn{2}{|c|}{ PA $(n=21)$} & \multicolumn{2}{|c|}{ HC $(n=22)$} & \multirow[t]{2}{*}{$\chi^{2}, F$} & \multirow[t]{2}{*}{$p$} \\
\hline & $M$ & $S D$ & $M$ & $S D$ & & \\
\hline Gender & \multicolumn{2}{|c|}{6 females } & \multicolumn{2}{|c|}{10 females } & 1.31 & 0.252 \\
\hline Age in years & 28.38 & 10.11 & 25.68 & 6.93 & 1.05 & 0.311 \\
\hline US intensity (mA) & 1.94 & 0.90 & 1.99 & 1.39 & 0.02 & 0.879 \\
\hline US intensity rating & 5.33 & 1.46 & 5.18 & 1.01 & 0.16 & 0.693 \\
\hline STAI Trait & 40.90 & 8.69 & 33.41 & 6.06 & 10.85 & 0.002 \\
\hline PFS & 3.10 & 1.92 & 0.00 & 0.00 & 53.17 & $<0.001$ \\
\hline PASQ & 42.38 & 24.36 & 0.00 & 0.00 & 66.69 & $<0.001$ \\
\hline PACQ & 21.95 & 12.32 & 0.00 & 0.00 & 69.95 & $<0.001$ \\
\hline$A Q$ & 17.67 & 13.41 & 0.00 & 0.00 & 38.23 & $<0.001$ \\
\hline
\end{tabular}

ASI, Anxiety Sensitivity Index; STAI, State-Trait-Anxiety-Inventory; BDI, Beck Depression Inventar; PFS, Panic Frequency Scale; PASQ, Panic Attack Symptoms Questionnaire; PACQ, Panic Attack Cognitions Questionnaire; AQ, Avoidance Questionnaire. Bold values indicates significant values.

in valence $\left(F_{(1,41)}=0.99, p=0.327, \eta_{\mathrm{p}}^{2}=0.023\right)$, arousal $\left(F_{(1,41)}=0.00, \quad p=0.998, \quad \eta_{\mathrm{p}}^{2}=0.000\right)$, and anxiety $\left(F_{(1,41)}=0.621, p=0.435, \eta_{\mathrm{p}}^{2}=0.015\right)$, and they elicited similar SCLs $\left(F_{(1,41)}=3.14, p=0.084, \eta_{\mathrm{p}}^{2}=0.071\right)$. However, PA compared to $\mathrm{HC}$ reported overall higher arousal $\left(F_{(1,41)}=5.68, p=0.022, \eta_{\mathrm{p}}^{2}=0.122\right)$ and anxiety $\left(F_{(1,41)}=16.01, p<0.001, \eta_{\mathrm{p}}^{2}=0.281\right)$. Figure 1 depicts these findings.

\section{Acquisition Phase}

First, we found significant context effects indicating successful conditioning for all dependent variables, i.e., valence $\left(F_{(1,41)}=18.85, p<0.001, \eta_{\mathrm{p}}^{2}=0.315\right)$, arousal $\left(F_{(1,41)}=29.93\right.$, $\left.p<0.001, \eta_{\mathrm{p}}^{2}=0.422\right)$, anxiety $\left(F_{(1,41)}=8.10, p=0.007\right.$, $\left.\eta_{\mathrm{p}}^{2}=0.165\right)$, contingency rating $\left(F_{(1,41)}=169.27, p<0.001\right.$, $\left.\eta_{\mathrm{p}}^{2}=0.805\right)$, startle responses $\left(F_{(1,41)}=5.06, p=0.030, \eta_{\mathrm{p}}^{2}=0.110\right)$, and $\operatorname{SCL}\left(F_{(1,41)}=6.08, p=0.018, \eta_{\mathrm{p}}^{2}=0.129\right)$.

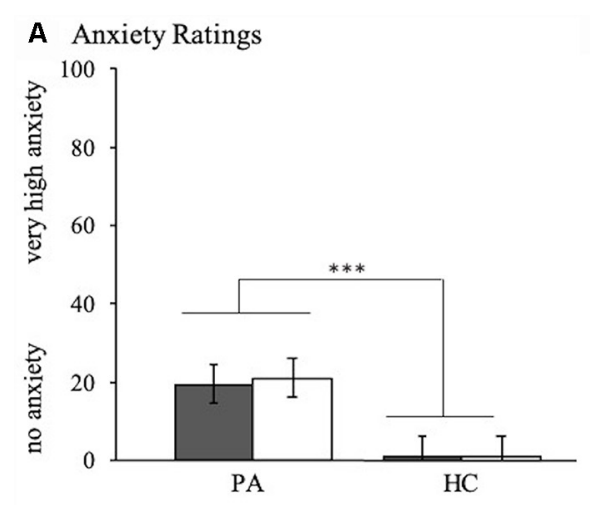

C Valence Ratings

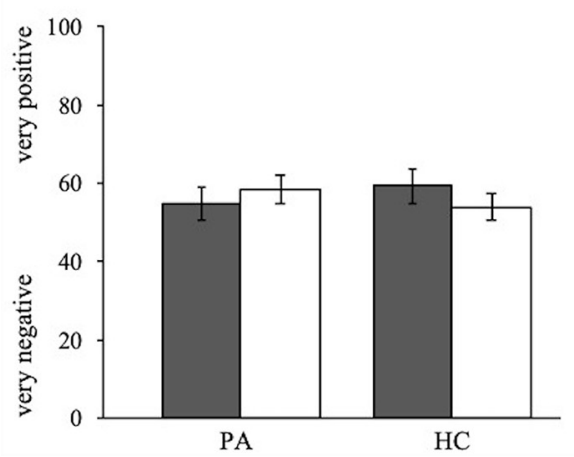

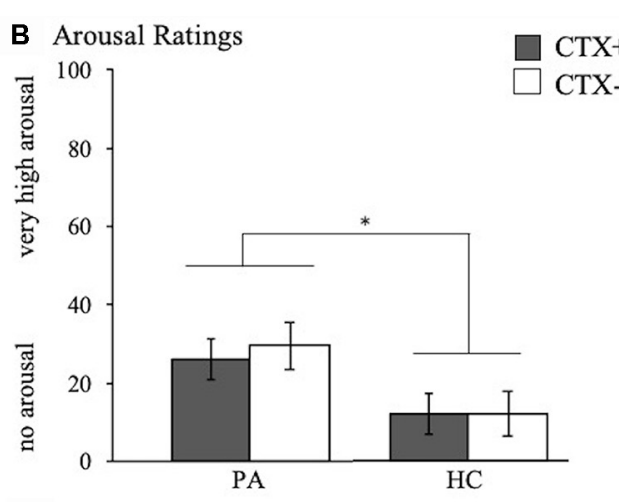

D Skin Conductance Level

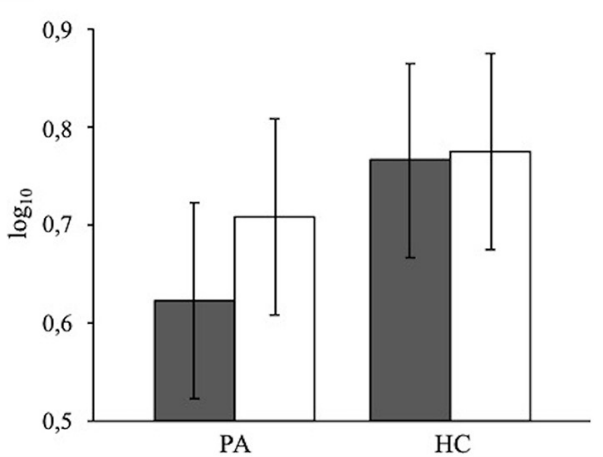

FIGURE 1 | Anxiety (A), arousal (B), and valence (C) ratings as well as skin conductance level (SCL) (D) of participants with panic attacks (PA, left bars) and healthy controls ( $\mathrm{HC}$, right bars) to the CTX+ (gray) and the CTX - (white) during the exploration phase. Depicted are mean responses (means and standard errors). ${ }^{*} p<0.050,{ }^{* * *} p<0.001$ 

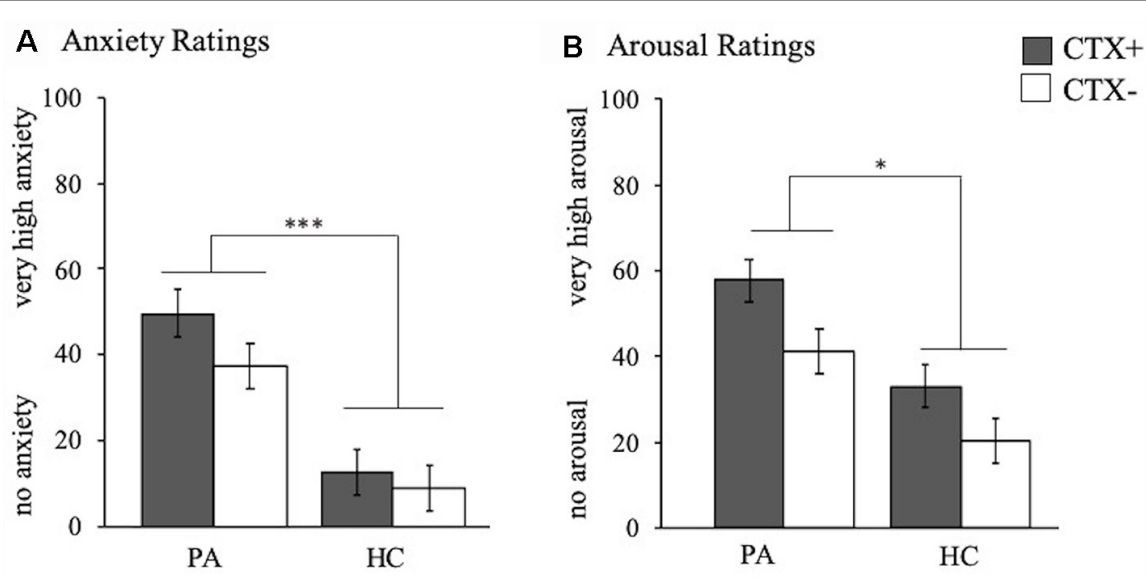

C Valence Ratings

D Contingency Ratings
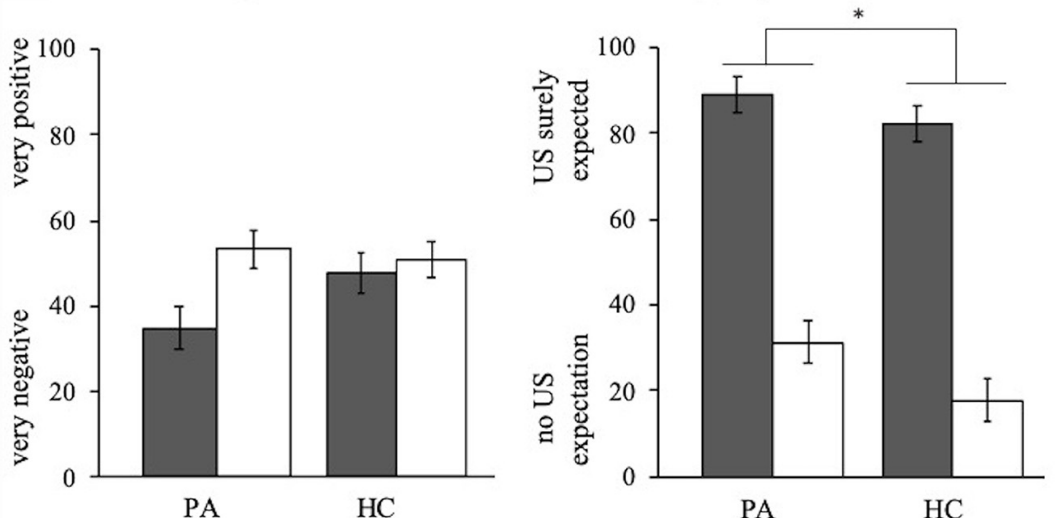

E Startle Responses

F Skin Conductance Level

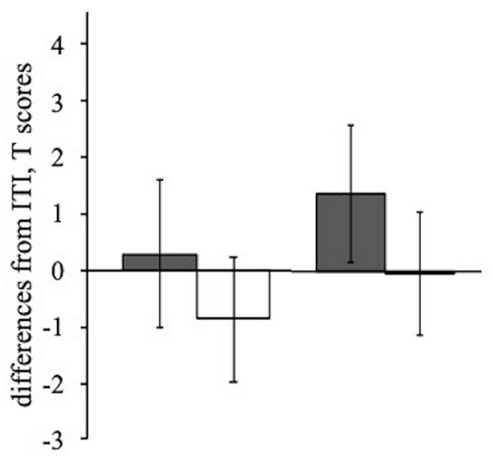

PA

$\mathrm{HC}$

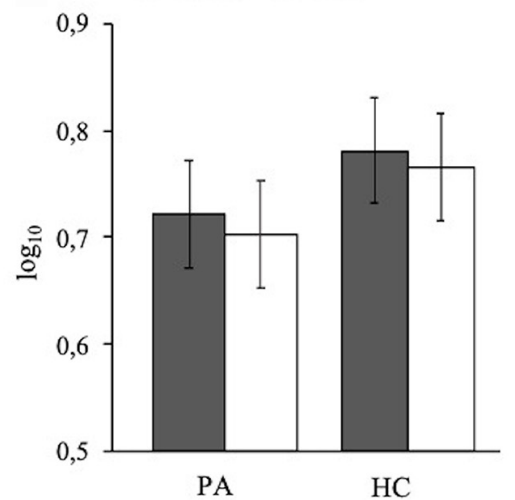

FIGURE 2 | Anxiety (A), arousal (B), valence (C), and contingency (D) ratings as well as startle amplitude (E) and SCL (F) of participants with PA (left bars) and HC (right bars) to the CTX+ (gray) and the CTX- (white) during the acquisition phase. Depicted are mean responses (means and standard errors). ${ }^{*} p<0.050$,

*** $p<0.001$.

Second, as depicted in Figure 2, PA vs. HC exhibited generally increased anxiety $\left(F_{(1,41)}=26.24, p<0.001, \eta_{\mathrm{p}}^{2}=0.390\right)$, arousal $\left(F_{(1,41)}=13.78, p=0.001, \eta_{\mathrm{p}}^{2}=0.252\right)$, and contingency ratings $\left(F_{(1,41)}=8.04, p=0.007, \eta_{\mathrm{p}}^{2}=0.164\right)$, while groups did not differ in valence ratings or both physiological measures (all $p s>0.382$ ).

Finally, a significant Context $\times$ Group interaction for valence ratings $\left(F_{(1,41)}=10.25, p=0.003, \eta_{\mathrm{p}}^{2}=0.200\right)$ revealed a stronger differential responding of individuals with $\mathrm{PA}$ compared to $\mathrm{HC}$ (Figure 4C, ACQ).

\section{Generalization Phase}

Analyses revealed for both anxiety and arousal ratings significant context effects (anxiety: $F_{(2,82)}=12.93, p<0.001, \eta_{\mathrm{p}}^{2}=0.240$; arousal; $\left.F_{(2,82)}=14.85, p<0.001, \eta_{\mathrm{p}}^{2}=0.266\right)$, significant 
A Anxiety Ratings

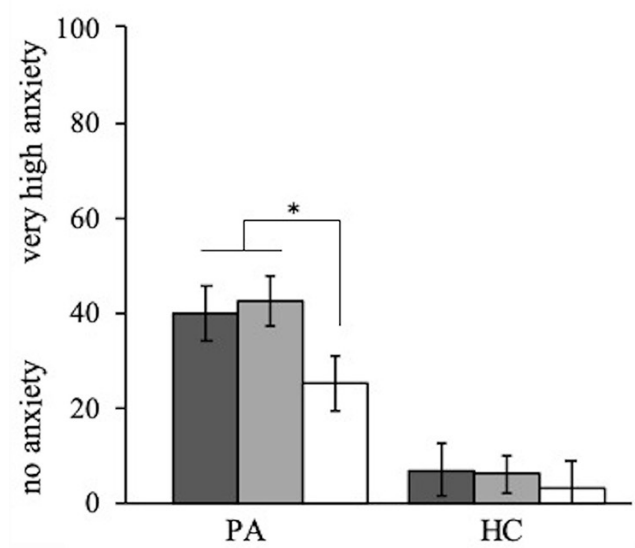

C Valence Ratings

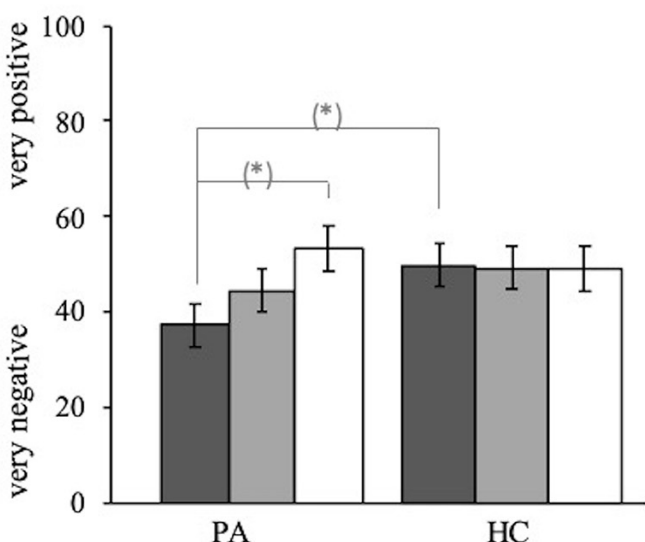

E Startle Responses

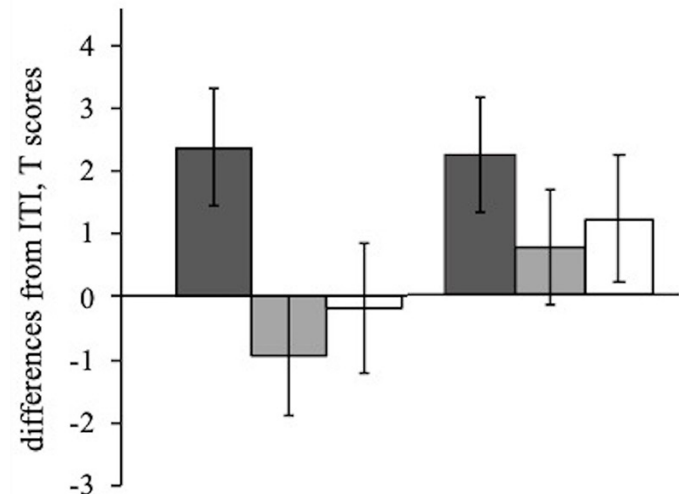

PA

$\mathrm{HC}$
B Arousal Ratings

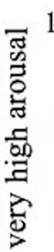

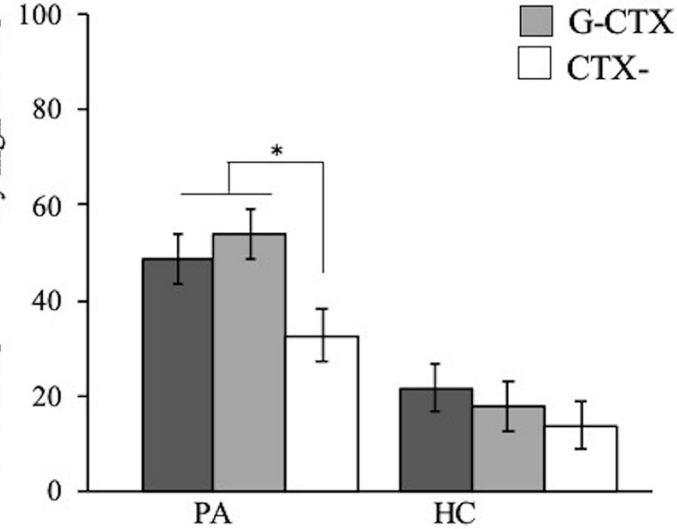

D Contingency Ratings

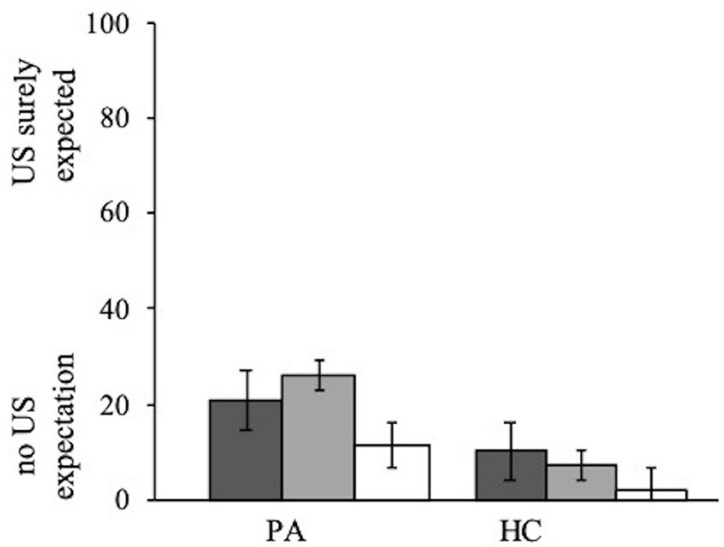

F Skin Conductance Level

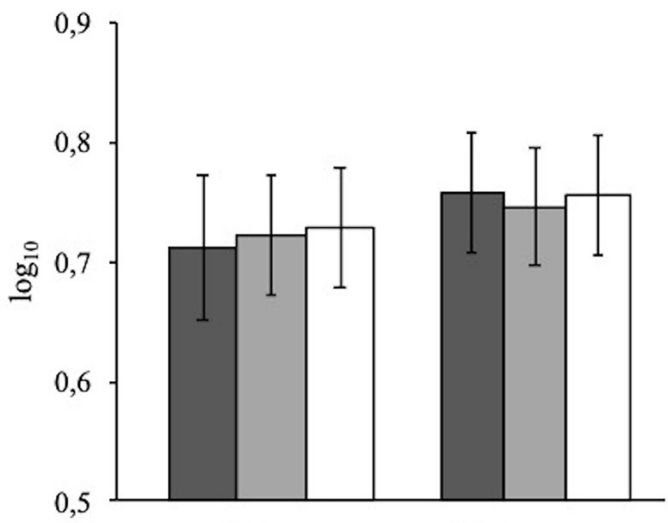

PA

CTX+

G-CTX

CTX-
$\mathrm{HC}$

FIGURE 3 | Anxiety (A), arousal (B), valence (C), and contingency (D) ratings as well as startle amplitude (E) and SCL (F) of participants with PA (left bars) and HC (right bars) to the CTX+ (gray) and the CTX- (white) during the generalization phase (GEN). Depicted are mean responses (means and standard errors). ${ }^{*} p<0.050$, (*)indicates only marginally significant results.

group effects (anxiety: $F_{(1,41)}=22.86, p<0.001, \eta_{\mathrm{p}}^{2}=0.358$ arousal: $\left.F_{(1,41)}=24.08, p<0.001, \eta_{\mathrm{p}}^{2}=0.370\right)$, and significant Context $\times$ Group interactions (anxiety: $F_{(2,82)}=6.35, p=0.003$, $\eta_{\mathrm{p}}^{2}=0.134 ;$ arousal: $\left.F_{(2,82)}=5.90, p=0.005, \eta_{\mathrm{p}}^{2}=0.126\right)$, and for valence ratings a marginally significant Context $\times$ Group interaction $\left(F_{(2,82)}=2.56, p=0.087, \eta_{\mathrm{p}}^{2}=0.083\right.$; Figure 3).

Further analyses of the interaction effects indicated that PA vs. HC showed overgeneralization of conditioned anxiety as 
A Anxiety Ratings

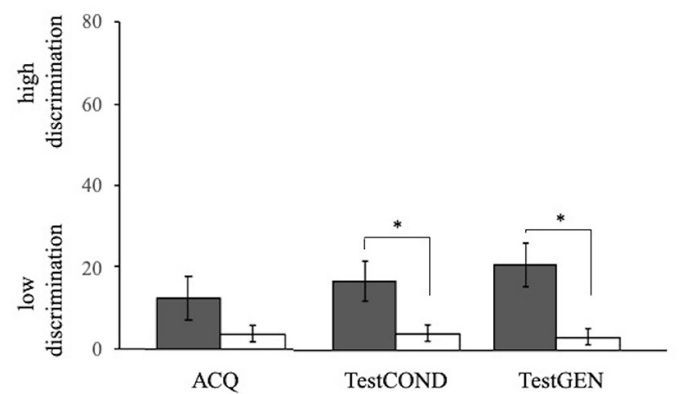

C Valence Ratings

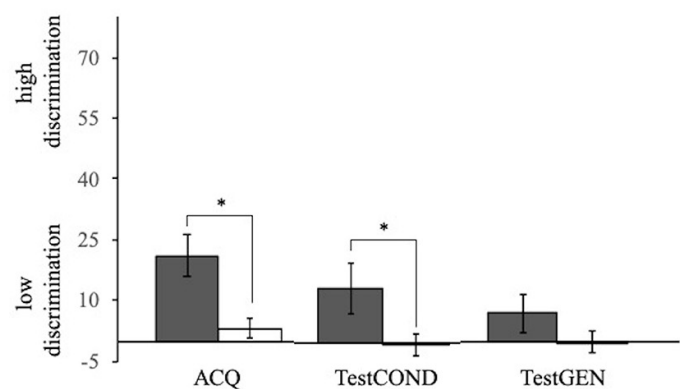

E Startle Responses

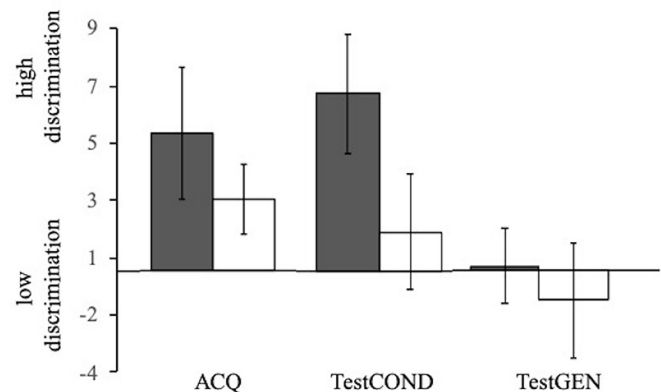

B Arousal Ratings

PA

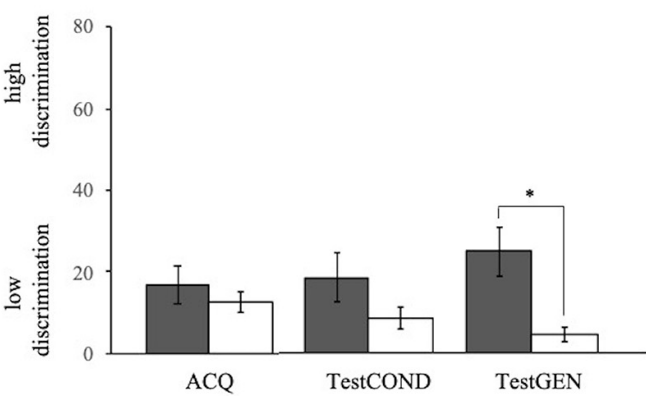

D Contingency Ratings

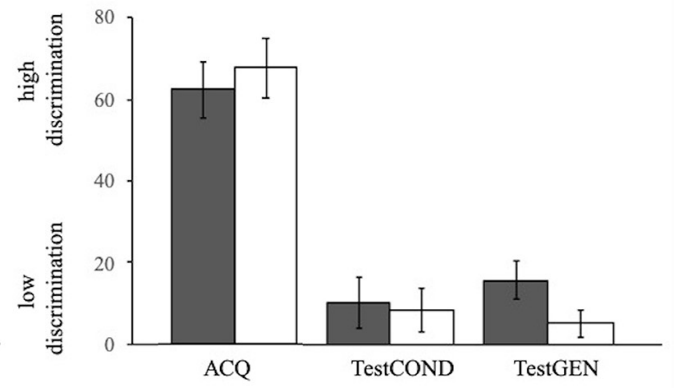

F Skin Conductance Level

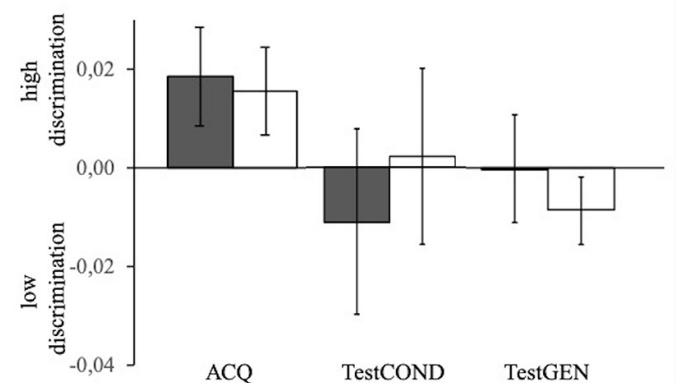

FIGURE 4 | Anxiety (A), arousal (B), valence (C), and contingency (D) ratings as well as startle amplitude (E) and SCL (F) of participants with PA (gray) and HC (white) during the acquisition phase and the generalization test phase. Depicted are mean differential responses (means and standard errors) relative to CTX-, i.e., for acquisition (ACQ) CTX+ minus CTX-, and for generalization CTX+ minus CTX - (testCOND) and G-CTX minus CTX - (testGEN). * $p<0.050$.

indicated by stronger responses to G-CTX relative to CTX - for anxiety $\left(t_{(41)}=3.05, p=0.004\right.$; Figure $4 \mathrm{~A}$; testGEN) and arousal ratings $\left(t_{(41)}=3.34, p=0.002\right.$; Figure $4 \mathrm{~B}$; testGEN).

Following-up the interaction effects regarding maintenance of conditioning effects revealed for PA vs. HC increased responses to $\mathrm{CTX}+$ relative to $\mathrm{CTX}-$ for anxiety ratings $\left(t_{(41)}=2.42, p=0.020\right.$; Figure 4A; TestCON) and valence ratings $\left(t_{(41)}=2.09, p=0.043\right.$; Figure 4C; TestCON $)$ indicating increased maintenance of conditioning effects.

Moreover, we found significant between-group effects for the CTX+ and the CTX-. More precise, PA individuals show higher anxiety and arousal ratings for the anxiety context (anxiety: $t_{(40)}=3,771, p=0.001$; arousal: $t_{(40)}=2,397, p=0.021$ ) and the safety context (anxiety: $t_{(40)}=3,490, p=0.001$; arousal: $\left.t_{(40)}=2,256, p=0.030\right)$ as compared to HC.

No interaction effects, but main effects of context were found for contingency ratings $\left(F_{(2,82)}=5.72, p=0.005, \eta_{\mathrm{p}}^{2}=0.122\right)$ and startle responses $\left(F_{(2,82)}=6.91, p=0.002, \eta_{\mathrm{p}}^{2}=0.144\right)$; both groups expected the US to occur in CTX+ $\left(F_{(1,41)}=5.25\right.$, $\left.p=0.027, \eta_{\mathrm{p}}^{2}=0.114\right)$ and in G-CTX $\left(F_{(1,41)}=13.29, p=0.001\right.$, $\left.\eta_{\mathrm{p}}^{2}=0.245\right)$ more likely than in CTX- indicating generalization, and both groups exhibited stronger startle responses in CTX+ compared to both CTX- $\left(F_{(1,41)}=7.04, p=0.011, \eta_{\mathrm{p}}^{2}=0.147\right)$ and G-CTX $\left(F_{(1,41)}=12.66, p=0.001, \eta_{\mathrm{p}}^{2}=0.236\right)$ indicating maintenance of conditioned anxiety.

A main effect of group $\left(F_{(1,41)}=5.16, p=0.028, \eta_{\mathrm{p}}^{2}=0.112\right)$ for contingency ratings indicates a generally increased US 
expectancy in PA compared to HC. Analyses for SCL revealed no significant effects (all $p s>0.619$ ).

\section{DISCUSSION}

The current study compared individuals with PA with HC regarding conditioning and generalization of contextual anxiety with the hypotheses that individuals with PA show heightened and persevered context conditioning as well as generalized anxiety responses. First, results revealed successful acquisition of contextual anxiety in both groups indicated by discriminative responses to the anxiety vs. the safety context for anxiety, arousal, valence and contingency ratings and for startle responses and SCLs. These results confirm the VR-paradigm's success in inducing contextual anxiety (Baas et al., 2004, 2008; Andreatta et al., 2015a, 2017; Genheimer et al., 2017).

Second, PA compared to HC exhibited heightened contextual conditioning, i.e., greater differential responding to CTX+ vs. CTX - for valence ratings after acquisition and for anxiety and valence ratings after the generalization test. As no US was delivered during the GEN, extinction learning may have been initiated during this phase (Milad and Quirk, 2012). Considering the significant main effect of context in ratings that were collected after the GEN, we conclude that this extinction learning was slow and that the implemented trials were not sufficient for extinction. We conclude that individuals with $\mathrm{PA}$, as high trait anxious individuals (Glotzbach-Schoon et al., 2013b), are prone to associate unpredictable threats with a context and to continuously respond with increased anxiety to this context as compared to a safety context, at least on an explicit evaluative level.

Third, we revealed stronger generalization of contextual anxiety in PA than in $\mathrm{HC}$ as indexed by anxiety and arousal ratings. This first observation of overgeneralization of contextual anxiety related to PA extends previous reports of overgeneralization of cued fear in anxiety (Lissek and Grillon, 2010; Lissek et al., 2014) and PDs (Lissek et al., 2010). Notably, such over-generalization in PA may be related to the increased anxiety responses to CTX+ vs. CTX-. As contextual conditioning may be based on configural (the context as whole, e.g., office) and/or elemental (the single elements, e.g., chair, desk, etc., Rudy, 2009) representations, it might be speculated that the increased responding to the CTX+ and the G-CTX relative to CTX- have the same cause, increased responding to threat-related elements.

Fourth, participants with PA compared to HC reported overall higher levels of arousal and anxiety as well as generally higher contingency ratings throughout the experiment. These findings validate the groups' characteristics and confirm the assumption that $\mathrm{PD}$ patients are characterized by exaggerated threat appraisal (Beck and Clark, 1997; Beck et al., 2005) and a tendency to overestimate the likelihood of threat (Amrhein et al., 2005; Lissek et al., 2010; Wiemer and Pauli, 2016a,b).

Critically, these findings were not matched by physiological anxiety measures. Specifically, we expected heightened context conditioning reflected in startle responses based on GlotzbachSchoon et al. (2013c), who examined high vs. low traitanxious individuals with a similar VR paradigm, and Grillon et al. (2008), who observed increased startle responses in PD patients compared to $\mathrm{HC}$ in an unpredictable threat condition. As the observed startle differences descriptively point in the expected direction (see Figure 4E) we expect that future studies with larger samples or diagnosed PD patients will be able to reveal startle effects. Especially since startle probes may impair learning (Sjouwerman et al., 2016), future studies should examine larger samples to have a greater power to reveal physiological effects.

Like in our previous context conditioning and generalization studies in healthy participants, we found context generalization effects for ratings only, but no hint of generalization for startle responses (Andreatta et al., 2015b, 2017). Indeed, this study revealed that startle responses of PA and HC clearly differed between the anxiety and the safety context during acquisition but were very similar for the generalization and the safety context. This may have methodological reasons as our test used one generalization context only which may have been too different from the anxiety context. Therefore, future studies on context conditioning should also use various generalization contexts to allow mapping of generalization gradients as previous cue generalization studies did (e.g., Lissek et al., 2008, 2010, 2014).

In sum, the current study revealed clear context conditioning effects for all participants and generally enhanced anxiety responses in individuals with PA compared to $\mathrm{HC}$ as indicated by physiological and verbal measures of anxiety. Importantly, we revealed on an evaluative verbal level heightened acquisition and increased generalization of contextual anxiety in individuals with PA compared to $\mathrm{HC}$ and speculate that both effects are risk factors for PD and/or agoraphobia. Such contextual conditioning and generalization processes may be the basis for developing PD and agoraphobia as they may cause anxiety in and avoidance of various contexts (e.g., shopping malls, crowded spaces), and may motivate withdrawal to safety contexts (e.g., the home).

\section{ETHICS STATEMENT}

The study was approved approved by the Ethics Committee of the Medical Faculty of the University of Würzburg. All participants gave informed consent. The authors assert that all procedures contributing to this work comply with the ethical standards of the relevant national and institutional committees on human experimentation and with the Helsinki Declaration of 1975, as revised in 2008.

\section{AUTHOR CONTRIBUTIONS}

DN was responsible for the design of the work and the data collection; carried out the data analysis under the supervision of MA; and drafted the article. MA and PP critically revised the article. PP gave the final approval of the version to be published. All authors contributed to the interpretation of the results. 


\section{FUNDING}

The work was supported by the Collaborative Research Center "Fear, Anxiety, Anxiety Disorders," SFB-TRR 58 project B01. This publication was funded

\section{REFERENCES}

Alpers, G., and Pauli, P. (2001). Angstsensitivitäts-Index. Würzburg: JuliusMaximilians Universität.

American Psychiatric Association. (2013). Diagnostic and Statistical Manual of Mental Disorders. 5th Edn. Arlington, VA: American Psychiatric Publishing.

Amrhein, C., Pauli, P., Dengler, W., and Wiedemann, G. (2005). Covariation bias and its physiological correlates in panic disorder patients. J. Anxiety Disord. 19, 177-191. doi: 10.1016/j.janxdis.2004.01.004

Andreatta, M., Glotzbach-Schoon, E., Mühlberger, A., Schulz, S. M., Wiemer, J., and Pauli, P. (2015a). Initial and sustained brain responses to contextual conditioned anxiety in humans. Cortex 63, 352-363. doi: 10.1016/j.cortex.2014. 09.014

Andreatta, M., Leombruni, E., Glotzbach-Schoon, E., Pauli, P., and Mühlberger, A. (2015b). Generalization of contextual fear in humans. Behav. Ther. 46, 583-596. doi: 10.1016/j.beth.2014.12.008

Andreatta, M., Mühlberger, A., Yarali, A., Gerber, B., and Pauli, P. (2010). A rift between implicit and explicit conditioned valence after pain-relief learning in humans. Proc. R. Soc. B Biol. Sci. 277, 2411-2416. doi: 10.1098/rspb.2010.0103

Andreatta, M., Neueder, D., Glotzbach-Schoon, E., Mühlberger, A., and Pauli, P. (2017). Effects of context preexposure and delay until anxiety retrieval on generalization of contextual anxiety. Learn. Mem. 24, 43-54. doi: 10.1101/lm. 044073.116

Baas, J. M., Nugent, M., Lissek, S., Pine, D. S., and Grillon, C. (2004). Fear conditioning in virtual reality contexts: a new tool for the study of anxiety. Biol. Psychiatry 55, 1056-1060. doi: 10.1016/s0006-3223(04)00347-6

Baas, J. M. P., Ooijen, L., Goudriaan, A., and Kenemans, J. L. (2008). Failure to condition to a cue is associated with sustained contextual fear. Acta. Psychologica. 127, 581-592. doi: 10.1016/j.actpsy.2007.09.009

Başoğlu, M., Marks, I. M., Kiliç, C., Swinson, R. P., Noshirvani, H., Kuch, K., et al. (1994). Relationship of panic, anticipatory anxiety, agoraphobia and global improvement in panic disorder with agoraphobia treated with alprazolam and exposure. Br. J. Psychiatry 164, 647-652. doi: 10.1192/bjp.164.5.647

Beck, A. T., and Clark, D. A. (1997). An information processing model of anxiety: automatic and strategic processes. Behav. Res. Ther. 35, 49-58. doi: 10.1016/s0005-7967(96)00069-1

Beck, A. T., Emery, G., and Greenberg, R. L. (2005). Anxiety Disorders and Phobias: A Cognitive Perspective. New York, NY: Basic Books.

Blumenthal, T. D., Cuthbert, B. N., Filion, D. L., Hackley, S., Lipp, O. V., and van Boxtel, A. (2005). Committee report: guidelines for human startle eyeblink electromyographic studies. Psychophysiology 42, 1-15. doi: 10.1111/j.14698986.2005.00271.x

Boucsein, W., Fowles, D. C., Grimnes, S., Ben-Shakhar, G., Roth, W. T., Dawson, M. E., et al. (2012). Publication recommendations for electrodermal measurements. Psychophysiology 49, 1017-1034. doi: 10.1111/j.1469-8986. 2012.01384.x

Clum, G. A., Broyles, S., Borden, J., and Watkins, P. L. (1990). Validity and reliability of the panic attack symptoms and cognitions questionnaires. J. Psychopathol. Behav. Assess. 12, 233-245. doi: 10.1007/bf00960620

Clum, G., Roodman, A., Febbraro, G., and Wright, J. (1995). CPP: comprehensive panic profile. Unpublished Manuscript

Dymond, S., Dunsmoor, J. E., Vervliet, B., Roche, B., and Hermans, D. (2015). Fear generalization in humans: systematic review and implications for anxiety disorder research. Behav. Ther. 46, 561-582. doi: 10.1016/j.beth.2014.10.001

Genheimer, H., Andreatta, M., Asan, E., and Pauli, P. (2017). Reinstatement of contextual conditioned anxiety in virtual reality and the effects of transcutaneous vagus nerve stimulation in humans. Sci. Rep. 7:17886. doi: 10.1038/s41598-017-18183-3

Glotzbach, E., Ewald, H., Andreatta, M., Pauli, P., and Mühlberger, A. (2012). Contextual fear conditioning predicts subsequent avoidance behaviour in a by the German Research Foundation (Deutsche Forschungsgemeinschaft, DFG; 44541416) and the University of Wuerzburg (Julius-MaximiliansUniversität Würzburg) in the funding programme Open Access Publishing.

virtual reality environment. Cogn. Emot. 26, 1256-1272. doi: 10.1080/02699931 2012.656581

Glotzbach-Schoon, E., Andreatta, M., Mühlberger, A., and Pauli, P. (2013a). Context conditioning in virtual reality as a model for pathological anxiety. e-Neuroforum 4, 63-70. doi: 10.1007/s13295-013-0047-z

Glotzbach-Schoon, E., Andreatta, M., Reif, A., Ewald, H., Tröger, C., Baumann, C., et al. (2013b). Contextual fear conditioning in virtual reality is affected by 5HTTLPR and NPSR1 polymorphisms: effects on fear-potentiated startle. Front. Behav. Neurosci. 7:31. doi: 10.3389/fnbeh.2013.00031

Glotzbach-Schoon, E., Tadda, R., Andreatta, M., Tröger, C., Ewald, H., Grillon, C., et al. (2013c). Enhanced discrimination between threatening and safe contexts in high-anxious individuals. Biol. Psychol. 93, 159-166. doi: 10.1016/j. biopsycho.2013.01.011

Gorka, S. M., Lieberman, L., Shankman, S. A., and Phan, K. L. (2017). Startle potentiation to uncertain threat as a psychophysiological indicator of fear-based psychopathology: an examination across multiple internalizing disorders. J. Abnorm. Psychol. 126, 8-18. doi: 10.1037/abn0000233

Grillon, C. (2008). Models and mechanisms of anxiety: evidence from startle studies. Psychopharmacology 199, 421-437. doi: 10.1007/s00213-0071019-1

Grillon, C., Ameli, R., Goddard, A., Woods, S. W., and Davis, M. (1994). Baseline and fear-potentiated startle in panic disorder patients. Biol. Psychiatry 35, 431-439. doi: 10.1016/0006-3223(94)90040-x

Grillon, C., Baas, J. M. P., Cornwell, B., and Johnson, L. (2006). Context conditioning and behavioral avoidance in a virtual reality environment: effect of predictability. Biol. Psychiatry 60, 752-759. doi: 10.1016/j.biopsych.2006. 03.072

Grillon, C., Lissek, S., Rabin, S., McDowell, D., Dvir, S., and Pine, D. S. (2008). Increased anxiety during anticipation of unpredictable but not predictable aversive stimuli as a psychophysiologic marker of panic disorder. Am. J. Psychiatry 165, 898-904. doi: 10.1176/appi.ajp.2007.07101581

Grillon, C., Pine, D. S., Lissek, S., Rabin, S., Bonne, O., and Vythilingam, M. (2009). Increased anxiety during anticipation of unpredictable aversive stimuli in posttraumatic stress disorder but not in generalized anxiety disorder. Biol. Psychiatry 66, 47-53. doi: 10.1016/j.biopsych.2008.12.028

Hautzinger, M., Keller, F., and Kühner, C. (2006). Beck Depressions-Inventar (BDI-II). Frankfurt: Harcourt Test Services Frankfurt.

Krohne, H. W., Egloff, B., Kohmann, C. W., and Tausch, A. (1996). Untersuchungen mit einer deutschen version der "positive and negative affect schedule" (PANAS). Diagnostica 42, 139-156.

Laux, L., Glanzmann, P., Schaffner, P., and Spielberger, C. (1981). State-TraitAnxiety-Inventory (STAI). Weinheim: Beltz-Test.

Lissek, S. (2012). Toward an account of clinical anxiety predicated on basic, neurally mapped mechanisms of Pavlovian fear-learning: the case for conditioned overgeneralization. Depress. Anxiety 29, 257-263. doi: 10.1002/da 21922

Lissek, S., Biggs, A. L., Rabin, S. J., Cornwell, B. R., Alvarez, R. P., Pine, D. S., et al. (2008). Generalization of conditioned fear-potentiated startle in humans: experimental validation and clinical relevance. Behav. Res. Ther. 46, 678-687. doi: 10.1016/j.brat.2008.02.005

Lissek, S., and Grillon, C. (2010). Overgeneralization of conditioned fear in the anxiety disorders: putative memorial mechanisms. Z. Psychol. J. Psychol. 218, 146-148. doi: 10.1027/0044-3409/a000022

Lissek, S., Kaczkurkin, A. N., Rabin, S., Geraci, M., Pine, D. S., and Grillon, C. (2014). Generalized anxiety disorder is associated with overgeneralization of classically conditioned fear. Biol. Psychiatry 75, 909-915. doi: 10.1016/j. biopsych.2013.07.025

Lissek, S., Rabin, S., Heller, R. E., Lukenbaugh, D., Geraci, M., Pine, D. S., et al. (2010). Overgeneralization of conditioned fear as a pathogenic marker of panic disorder. Am. J. Psychiatry 167, 47-55. doi: 10.1176/appi.ajp.2009.09030410 
Milad, M. R., and Quirk, G. J. (2012). Fear extinction as a model for translational neuroscience: ten years of progress. Annu. Rev. Psychol. 63, 129-151. doi: 10.1146/annurev.psych.121208.131631

Nelson, B. D., McGowan, S. K., Sarapas, C., Robison-Andrew, E. J., Altman, S. E., Campbell, M. L., et al. (2013). Biomarkers of threat and reward sensitivity demonstrate unique associations with risk for psychopathology. J. Abnorm. Psychol. 122, 662-671. doi: 10.1037/a0033982

Peterson, R. A., and Reiss, S. (1992). Anxiety Sensitivity Index. Hillsdale, NJ: Lawrence Erlbaum Associates.

Roy-Byrne, P. P., Stang, P., Wittchen, H. U., Ustun, B., Walters, E. E., and Kessler, R. C. (2000). Lifetime panic-depression comorbidity in the national comorbidity survey: association with symptoms, impairment, course and help-seeking. Br. J. Psychiatry 176, 229-235. doi: 10.1192/bjp.176. 3.229

Rudy, J. W. (2009). Context representations, context functions, and the parahippocampal-hippocampal system. Learn. Mem. 16, 573-585. doi: 10. 1101/lm.1494409

Sjouwerman, R., Niehaus, J., Kuhn, M., and Lonsdorf, T. B. (2016). Don't startle me-interference of startle probe presentations and intermittent ratings with fear acquisition. Psychophysiology 53, 1889-1899. doi: 10.1111/psyp. 12761

Tröger, C., Ewald, H., Glotzbach, E., Pauli, P., and Mühlberger, A. (2012). Does pre-exposure inhibit fear context conditioning? A virtual reality study. J. Neural Transm. 119, 709-719. doi: 10.1007/s00702-011 $-0757-8$
Wiemer, J., and Pauli, P. (2016a). Enhanced functional connectivity between sensorimotor and visual cortex predicts covariation bias in spider phobia. Biol. Psychol. 121, 128-137. doi: 10.1016/j.biopsycho.2016.01.007

Wiemer, J., and Pauli, P. (2016b). How fear-relevant illusory correlations might develop and persist in anxiety disorders: a model of contributing factors. J. Anxiety Disord. 44, 55-62. doi: 10.1016/j.janxdis.2016.10.008

Wittchen, H. U., Jacobi, F., Rehm, J., Gustavsson, A., Svensson, M., Jönsson, B. et al. (2011). The size and burden of mental disorders and other disorders of the brain in Europe 2010. Eur. Neuropsychopharmacol. 21, 655-679. doi: 10.1016/j. euroneuro.2011.07.018

Conflict of Interest Statement: PP is shareholder of a commercial company that develops virtual environment research systems.

The remaining authors declare that the research was conducted in the absence of any commercial or financial relationships that could be construed as a potential conflict of interest.

Copyright (c) 2019 Neueder, Andreatta and Pauli. This is an open-access article distributed under the terms of the Creative Commons Attribution License (CC BY). The use, distribution or reproduction in other forums is permitted, provided the original author(s) and the copyright owner(s) are credited and that the original publication in this journal is cited, in accordance with accepted academic practice. No use, distribution or reproduction is permitted which does not comply with these terms. 